\title{
Persistent enhancement of the HF pump-induced plasma line measured with a UHF diagnostic radar at HAARP
}

\author{
S. Oyama, ${ }^{1}$ B. J. Watkins, ${ }^{1}$ F. T. Djuth, ${ }^{2}$ M. J. Kosch, ${ }^{3,4}$ P. A. Bernhardt, ${ }^{5}$ \\ and C. J. Heinselman ${ }^{6}$ \\ Received 15 August 2005; revised 10 March 2006; accepted 15 March 2006; published 29 June 2006.
}

[1] Plasma lines excited by a powerful, high-frequency (HF) radio wave are studied using data obtained with an ultrahigh frequency (UHF) radar at HAARP (High Frequency Active Auroral Research Program) from 3 to 5 February 2005. Of particular interest is persistent enhancement of the radar backscatter power during HF on at several HF frequencies. The persistent enhancement is induced with the HF frequency slightly lower than $f o F 2$ by a few hundred $\mathrm{kHz}$; by contrast the persistent enhancement does not appear when the HF frequency is equal to and higher than $f_{o F}$ or lower than $f o F 2$ by more than $500 \mathrm{kHz}$. When persistent enhancements of the radar backscatter power appear, two case studies show that the local plasma frequency at the reflection height of the O-mode polarization wave is close to the second or third electron gyroharmonic frequencies, but one case study shows that the local plasma frequency at the reflection height is significantly different from the third electron gyroharmonic frequency.

Citation: Oyama, S., B. J. Watkins, F. T. Djuth, M. J. Kosch, P. A. Bernhardt, and C. J. Heinselman (2006), Persistent enhancement of the HF pump-induced plasma line measured with a UHF diagnostic radar at HAARP, J. Geophys. Res., 111, A06309, doi:10.1029/2005JA011363.

\section{Introduction}

[2] Many experiments involving the modification of the ionosphere with high-power, high-frequency (HF) radio waves have been performed in the past. These investigations make use of large ground-based facilities commonly referred to as HF facilities or heating facilities. The world's major HF facilities are (were) the Arecibo observatory, Puerto Rico (the Arecibo facility, $18.35^{\circ} \mathrm{N}, 66.75^{\circ} \mathrm{W}$ was operated from 1971 to 1978 ; and the Islote facility, $18.48^{\circ} \mathrm{N}$, $66.66^{\circ} \mathrm{W}$, was operated from 1981 to 1998 ), the European Incoherent Scatter (EISCAT) Tromsø site, Norway $\left(69.59^{\circ} \mathrm{N}, 19.23^{\circ} \mathrm{E}\right)$, the Space Plasma Exploration by Active Radar (SPEAR) at Svalbard, Norway $\left(78.15^{\circ} \mathrm{N}\right.$, $16.05^{\circ} \mathrm{E}$ ), HF Active Auroral Research Program (HAARP) in Gakona, Alaska $\left(62.39^{\circ} \mathrm{N}, 145.15^{\circ} \mathrm{W}\right)$, the High Power Auroral Stimulation (HIPAS) observatory near Fairbanks, Alaska $\left(64.87^{\circ} \mathrm{N}, 146.84^{\circ} \mathrm{W}\right)$, the Sura facility near Vasil'sursk, Russia $\left(56.13^{\circ} \mathrm{N}, 46.10^{\circ} \mathrm{E}\right)$, Kharkov observatory, Ukraine, Russia $\left(50.00^{\circ} \mathrm{N}, 36.2^{\circ} \mathrm{E}\right)$, and the Platteville, Colorado observatory (operated from 1970 to 1981,

\footnotetext{
${ }^{1}$ Geophysical Institute, University of Alaska Fairbanks, Fairbanks, Alaska, USA.

${ }^{2}$ Geospace Research, Inc., El Segundo, California, USA.

${ }^{3}$ Communication Systems, Lancaster University, Lancaster, UK.

${ }^{4}$ Honorary Research Fellow, University of Kwazulu-Natal, Durban, South Africa.

${ }^{5}$ Plasma Physics Division, Naval Research Laboratory, Washington DC, USA.

${ }^{6}$ SRI International, Menlo Park, California, USA
}

Copyright 2006 by the American Geophysical Union. 0148-0227/06/2005JA011363\$09.00 $\left.40.18^{\circ} \mathrm{N}, 104.73^{\circ} \mathrm{W}\right)$. Of these facilities, four are polar facilities (HAARP, EISCAT Tromsø and Svalbard, and HIPAS), and the remaining four are classified as midlatitude facilities. Only three have powerful incoherent scatter (IS) radars for supporting diagnostic measurements: Arecibo observatory, Tromsø and Svalbard EISCAT sites. The Arecibo radar operates at a center frequency of $430 \mathrm{MHz}$, and the two EISCAT IS radars at Tromsø operate at frequencies near $224 \mathrm{MHz}$ and $931 \mathrm{MHz}$, and $500 \mathrm{MHz}$ at Svalbard.

[3] Recently, an ultrahigh frequency (UHF) diagnostic radar was added to HAARP; it is located $\sim 2 \mathrm{~km}$ from the $\mathrm{HF}$ antenna array. This radar is tuned to a center frequency of $446 \mathrm{MHz}$ and therefore diagnoses the ionospheric plasma at a wave number similar to that of Arecibo observatory. The radar is a development version of the Advanced Modular Incoherent Scatter Radar (AMISR) that has been developed by the National Science Foundation and SRI International for incoherent scatter observations at other locations. The first ionospheric modification observations made with the HAARP UHF radar took place between 3 and 5 February 2005 and are the subject of the study described herein. During these experiments an eight-panel configuration was employed, which yielded a peak power of $256 \mathrm{~kW}$, an effective antenna aperture of $109.9 \mathrm{~m}^{2}$, and the system temperature of $120 \mathrm{~K}$. The antenna phased array was placed in the horizontal plane, and yielded $\mathrm{a} \sim 4.3^{\circ}$ for $3 \mathrm{~dB}$ half-width one-way beamwidth of the vertical beam. The radar beam can be steered to a maximum zenith angle of $\sim 30^{\circ}$ without significantly decreasing antenna gain or greatly increasing the beamwidth. HAARP's location makes it possible to point the radar beam parallel to the geomagnetic field in the $F$ region. The required geographic beam 
pointing coordinates are $15^{\circ}$ zenith angle and $204^{\circ}$ azimuth. Thus the HAARP UHF radar operates at a frequency close to the Arecibo IS radar, but the geomagnetic observing geometry is similar to that of EISCAT.

[4] Many HF ionospheric modification experiments have been conducted at EISCAT [Hagfors et al., 1983; Stubbe et al., 1985; Djuth et al., 1994; Isham et al., 1999; Rietveld et al., 2000] and Arecibo [Showen and Kim, 1978; Duncan and Sheerin, 1985; Djuth et al., 1986; Cheung et al., 1989; Djuth et al., 1990; Cheung et al., 1992; Isham and Hagfors, 1993]. The radars observed enhanced ion and plasma lines that originated from an altitude where HF pump waves caused local changes in the plasma density and temperature as well as plasma-wave turbulence. Important experimental information is provided from spectrum analysis of the radar backscatter from the ionosphere modified by artificially induced electromagnetic waves.

[5] Many of the spectral features of Langmuir turbulence excited by HF pump waves were initially interpreted in terms of the parametric decay instability (PDI) and the oscillating two-stream instability (OTSI) [e.g., Fejer and Kuo, 1973; Perkins et al., 1974]. This theory employs a weak turbulence approximation to the Zakharov model equations. However, altitude-averaged enhanced plasma line spectra detected with an IS radar exhibit two features that cannot be readily explained with this approximation. The first is a broad spectral component that starts at the decay line and rapidly decreases with frequency over a frequency interval of $30-100 \mathrm{kHz}$ in the direction of $f_{\text {radar, }}$, where $f_{\text {radar }}$ is the radar frequency [e.g., Kantor, 1974; Carlson and Duncan, 1977; Showen and Kim, 1978; Djuth, 1984; Djuth et al., 1986; Stubbe et al., 1992; Kohl et al., 1993]. The second feature is a weak displaced peak first noted by Djuth et al. [1986] in the band $f_{\text {radar }} \pm\left(f_{\mathrm{HF}}+\Delta\right)$, where $f_{\mathrm{HF}}$ is the HF pump frequency, and $\Delta=10-100 \mathrm{kHz}$. Other observations showed similar results [Cheung et al., 1989; Cheung et al., 1992; Kohl et al., 1993]. In addition, in many observations the radar echo appeared to originate near the point of HF reflection, which is inconsistent with theory based on the weak turbulence approximation [e.g., Muldrew and Showen, 1977; Birkmayer et al., 1986; Isham et al., 1987; Fejer et al., 1991; Isham and Hagfors, 1993; Sulzer and Fejer, 1994]. Strong Langmuir turbulence (SLT) theory provides the much needed new paradigm for the interpretation of the results. Density cavities referred to as solitons were found to occur near the point of HF reflection in the pioneering work of Petviashvilli [1976], Weatherall et al. [1982], Sheerin et al. [1982], Nicholson et al. [1984], and Payne et al. [1984]. This was followed by a series of theoretical studies focused on localized plasma states consisting of Langmuir oscillations trapped in a self-consistent density cavity. These entities were termed cavitons [Russell et al., 1988; DuBois et al., 1988; DuBois et al., 1990]. The broad HF pump-induced plasma line (HFPL) spectrum and the displaced peak discussed above are readily interpreted within the context of the caviton model [e.g., Cheung et al., 1989; DuBois et al., 1990; Cheung et al., 1992; Hanssen et al., 1992; DuBois et al., 1993a, 1993b; DuBois et al., 1995a, 1995b; DuBois et al., 2001]. The broad spectrum is the result of the collapse of localized states, which skew spectral components to frequencies less than $f_{\mathrm{HF}}$, and the displaced spectral feature is the "free mode," which is a freely propagating Langmuir wave. Both features occur at and below the critical layer. However, only the free mode follows dispersion relation for Langmuir waves in a magnetized plasma: $\omega_{\mathrm{L}}^{2}\left(k_{s}, z\right)=\omega_{p e}^{2}(z)+3 k_{s}^{2} V_{e}^{2}+\omega_{c e}^{2} \sin ^{2} \theta$ [DuBois et al., 1993a], where $k_{\mathrm{s}} \approx 2 k_{\text {radar, }} k_{\text {radar }}$ is magnitude of the radar wave vector $\boldsymbol{k}_{\text {radar }}, V_{\mathrm{e}}$ is thermal velocity of electrons, $\omega_{\text {pe }}$ and $\omega_{\text {ce }}$ are the electron plasma frequency and electron cyclotron frequencies, respectively, and $\theta$ is the angle between $\boldsymbol{k}_{\text {radar }}$ and the geomagnetic field. Altitude resolved HFPL and ion line spectra [Fejer et al., 1991; Sulzer and Fejer, 1994; Stubbe, 1996b; Kohl and Rieveld, 1996; Isham et al., 1999; Rietveld et al., 2000; Cheung et al., 2001; Djuth et al., 2004] have shown remarkable similarity to the predictions of DuBois et al. [1993a, 1993b, 2001].

[6] The SLT theory is based on an extension of Zakharov's model [Zakharov, 1972; DuBois et al., 1993a], which describes coupling of high-frequency Langmuir waves with low-frequency ion density fluctuations driven by artificially induced electromagnetic waves. The ponderomotive force of Langmuir waves generates cavitons within a several hundred meters of the O-mode reflection height where the HF frequency is equal to the local plasma frequency. Broadband Langmuir oscillations are generated by Langmuir collapse events along with narrow-banded freely propagating Langmuir modes. Parametric decay cascades develop at lower heights where wave number and frequency matching conditions are satisfied. The propagation of both the free mode cascade waves is determined by the Langmuir dispersion relation.

[7] HF pump-induced plasma lines observed with the IS radar contain several sharp peaks at a displacement of $\pm f_{\mathrm{HF}}$ from $f_{\text {radar }}$ and at offsets of $n=1,3,5 \ldots$ times the ion-acoustic frequency, $f_{i a}$, from $f_{\text {radar }} \pm f_{\mathrm{HF}}$, that is $f_{\text {radar }} \pm\left(f_{\mathrm{HF}}-n f_{i a}\right)$. The ion-acoustic frequency is dependent on the plasma temperature [Isham and Hagfors, 1993, equation (1)]. The former peak is known as the purely growing mode, which is due to the OTSI [Kantor, 1974; Carlson and Duncan, 1977; Walker, 1979; Nicholson et al., 1984; Sprague and Fejer, 1995; Stubbe, 1996a]. The latter peaks with the frequency offset of $f_{i a}$ and $n f_{i a}$ are known as the decay and the cascade lines, respectively.

[8] The focus of this paper is on persistent enhancements of the plasma line during $\mathrm{HF}$ on at several HF pump frequencies. Section 2 below outlines operational modes of the UHF diagnostic radar and the HAARP. Three examples of the persistent plasma line are presented in section 3. Section 4 discusses ionospheric conditions when the persistent plasma line appears.

\section{Experimental Details}

[9] The HAARP HF transmitter system was operated from 3 to 5 February 2005 in various modes with O- and $\mathrm{X}$-mode polarizations, directed toward the local geomagnetic field line at HAARP (azimuth: $204^{\circ}$, elevation: $75^{\circ}$ ) at several frequencies as shown in Table 1 . The present paper reports only about data obtained for selected intervals when persistent enhancements of the UHF diagnostic radar backscatter were observed. The pump duty cycle was also tabulated in Table 1. 
Table 1. HAARP Operations for the Selected Experiments on 3-5 February 2005

\begin{tabular}{|c|c|c|c|c|c|c|c|}
\hline Date & Start, UT & Stop, UT & Frequency, MHz & Polarization & Power, kW & ERP, MW & Pump Duty Cycle \\
\hline 0203 & 0200:00 & 0259:30 & 4.1 & $\mathrm{O}$ & 880 & 39 & $1^{\mathrm{a}}$ \\
\hline 0204 & 0300:00 & 0550:00 & 2.85 & $\mathrm{O} / \mathrm{X}$ & 880 & 16 & $2^{b}$ \\
\hline 0205 & 0135:00 & 0139:30 & 4.3 & $\mathrm{O}$ & 900 & 47 & $3^{c}$ \\
\hline 0205 & 0140:00 & 0209:30 & 4.5 & $\mathrm{O}$ & 900 & 53 & 3 \\
\hline 0205 & 0210:00 & 0219:30 & 5.35 & $\mathrm{O}$ & 900 & 83 & 3 \\
\hline 0205 & 0220:00 & 0229:30 & 4.95 & $\mathrm{O}$ & 900 & 69 & 3 \\
\hline 0205 & 0230:00 & 0244:30 & 4.6 & $\mathrm{O}$ & 900 & 56 & 3 \\
\hline
\end{tabular}

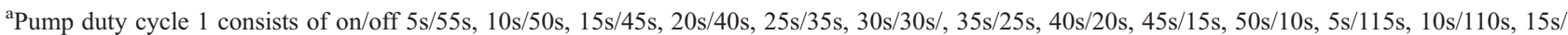
$105 \mathrm{~s}, 20 \mathrm{~s} / 100 \mathrm{~s}, 25 \mathrm{~s} / 95 \mathrm{~s}, 30 \mathrm{~s} / 90 \mathrm{~s}, 35 \mathrm{~s} / 85 \mathrm{~s}, 40 \mathrm{~s} / 80 \mathrm{~s}, 45 \mathrm{~s} / 75 \mathrm{~s}, 50 \mathrm{~s} / 70 \mathrm{~s}$.

${ }^{\mathrm{b}}$ Pump duty cycle 2 consists of $1 \mathrm{~min}$ off, 1 min O-mode on, 1 min off, $1 \mathrm{~min}$ X-mode on.

${ }^{\mathrm{c}}$ Pump duty cycle 3 consists of $5 \mathrm{~s}$ off, $5 \mathrm{~s}$ on, 110 s off, $180 \mathrm{~s}$ on.

[10] The UHF diagnostic radar beam was directed along the geomagnetic field line during all experiments discussed in this paper. It operated at a frequency of $446 \mathrm{MHz}$ with a $998-\mu$ s uncoded transmitter pulse and $100-\mathrm{kHz}$ sampling rate. An interpulse period (IPP) of $10 \mathrm{~ms}$ was used. This diagnostic radar had only one receiver to measure one of the up-shifted or down-shifted plasma lines.

[11] The ionosonde at HAARP was used to estimate $f_{o F} 2$ and other ionospheric parameters every 2 or $5 \mathrm{~min}$. The $f o F 2$ data were used in real time to determine optimum HF frequencies.

\section{Experimental Results}

\subsection{Case Study on 3 February 2005}

[12] Figure 1 shows color-coded time-frequency profile of power spectral density (PSD) of the down-shifted plasma line measured with the UHF diagnostic radar from 0201 to 0211 UT on 3 February 2005. The figure uses data integrated for $2 \mathrm{~s}$. The thick white lines show the HF on periods, which incrementally increase by $5 \mathrm{~s}$ each until $0210 \mathrm{UT}$, when a new pumping cycle begins. The diagnostic radar was not operated during the initial 5 -s on period because of technical troubles, which delayed starting the measurement. The data showed strongly enhanced signal returns just after the HF pump wave was turned on. This enhanced power is frequently termed as "overshoot." For the remainder of interval when the HF pump wave was on, there was a weaker persistent enhancement.

[13] When the plasma line overshoot was observed during $\mathrm{HF}$ on period, at least three cascade lines were developed together with the decay line in association with HF turn-on. The cascade lines appeared at near odd multiplies of the ion-acoustic frequency, which is about $4 \mathrm{kHz}$. The persistent plasma line appeared for all periods from beginning of the diagnostic radar operation at 0201 UT to 0208 UT, although the persistent plasma line induced at 0207 UT gradually became weak during HF on period. Persistent enhancements of the plasma line were not clearly seen after 0209 UT. Since the operational mode of the HF transmitter system was not changed for this experiment except for duration of the HF on/off period, some ionospheric conditions might change around 0208 UT. To

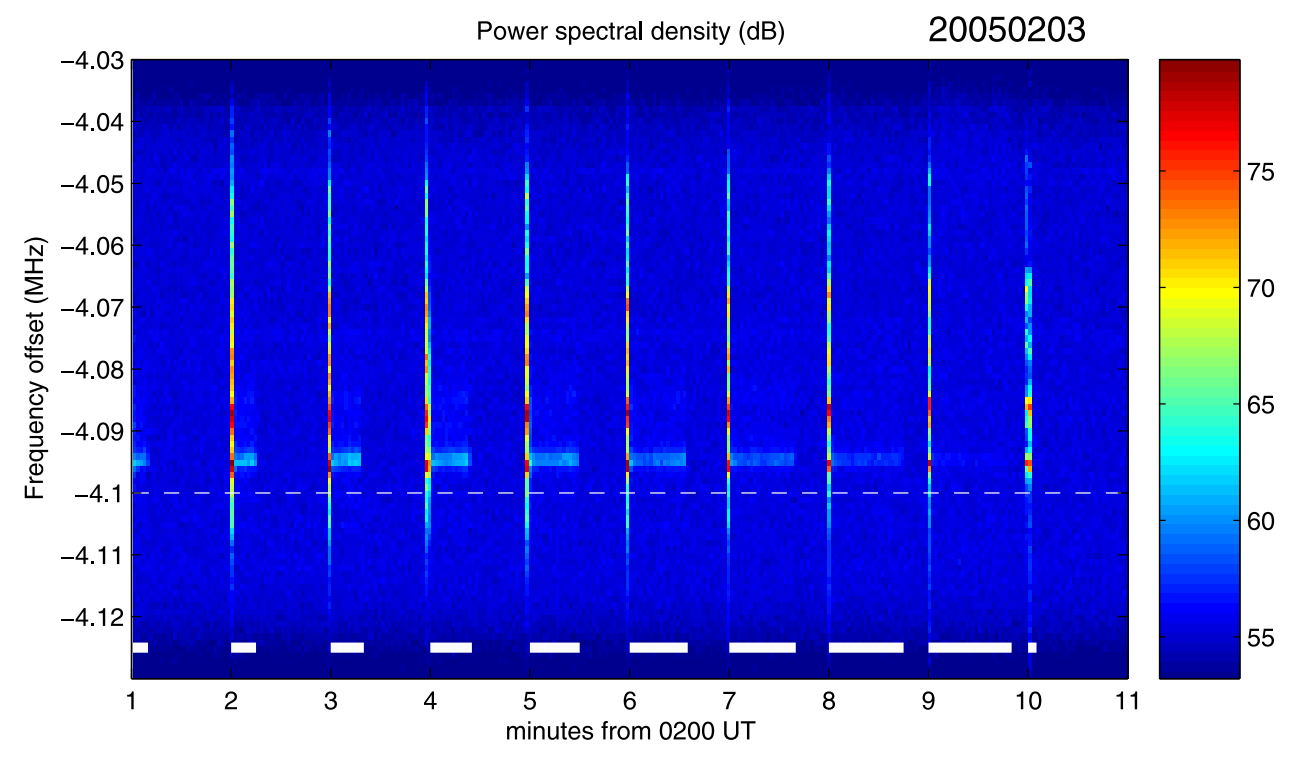

Figure 1. Color-coded time-frequency profile of power spectral density of the downshifted plasma line measured with the UHF diagnostic radar from 0201 to 0211 UT on 3 February 2005. The figure is plotted by using 2-s integrated data. White thick line shows time intervals for O-mode HF on. The dashed line shows the frequency offset from the UHF diagnostic radar frequency minus the HF pump frequency. 

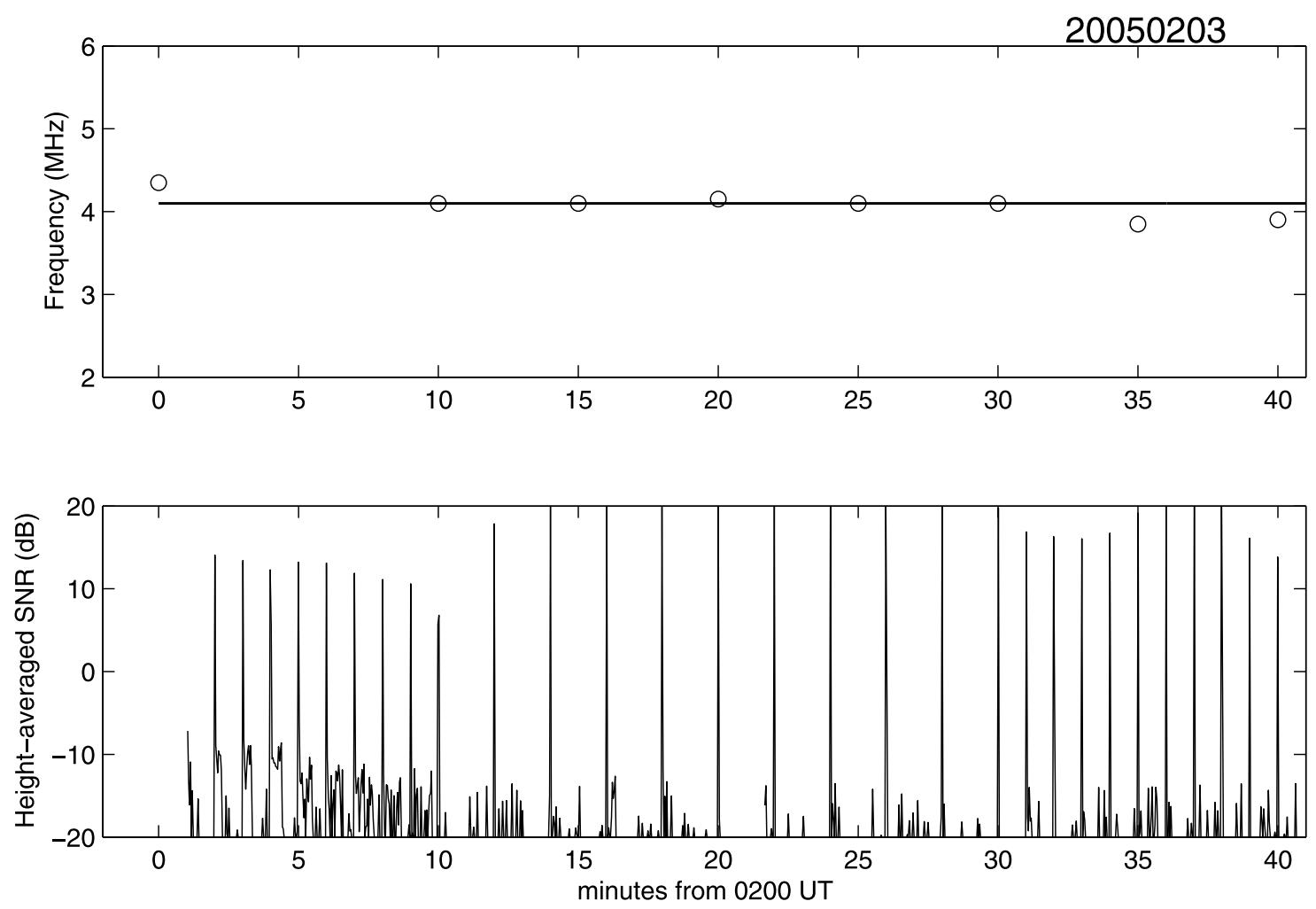

Figure 2. Temporal variations in $f o F 2$ measured with the HAARP ionosonde (open circle) and the HF pump frequency of $4.1 \mathrm{MHz}$ (solid line) from 0200 to 0240 UT on 3 February 2005. The lower panel shows temporal variations in the height-averaged SNR measured with the UHF diagnostic radar.

investigate that, we compare the HF pump frequency and foF 2 measured with the HAARP ionosonde as shown in Figure 2. Values of $f o F 2$ were obtained every 5 min except at 0205 UT. The upper panel of Figure 2 shows that $f_{o F}$ from 0200 to 0240 UT decreased with time from 4.35 to $3.90 \mathrm{MHz}$. The HF pump frequency of $4.1 \mathrm{MHz}$ at $0200 \mathrm{UT}$ was slightly lower than $f_{o} F 2$, and that at 0210 UT was equal to $f o F 2$. These frequency differences imply that the HF pump frequency was slightly lower than $f o F 2$ by a few hundred $\mathrm{kHz}$ when persistent enhancements of the plasma line were observed from 0201 to 0208 UT. When there were no persistent plasma line enhancements, the HF pump frequency was approximately equal to or higher than $f_{o F}$. The height-averaged signal-to-noise ratio (SNR) of radar backscatter power had a minimum value in a few seconds after HF turn-on when persistent plasma line enhancements were observed, and then increased to about $-9 \mathrm{~dB}$ keeping this level until HF turn-off.

[14] While the UHF diagnostic radar was fixed to look along the geomagnetic field line for these experiments, the ionosonde obtained most of its data from a wide beam directed vertically. To compare data from two radio instruments, we need to assume the ionospheric homogeneity in two different positions as discussed in section 4 .

\subsection{Case Study on $\mathbf{4}$ February 2005}

[15] Figure 3 shows color-coded time-frequency profile of PSD of the upshifted plasma line from 0317 to 0339 UT on 4 February 2005. The figure is plotted using data integrated for $2 \mathrm{~s}$. The HF pump frequency during this time interval was $2.85 \mathrm{MHz}$. Persistent plasma line enhancements were seen clearly during O-mode transmissions, except for 0337 to 0338 UT. No plasma lines were seen during X-mode pumping. The purely growing mode can be clearly seen at $2.85 \mathrm{MHz}$, and the decay and the first cascade lines are also clearly identified. Persistent plasma lines contained broad peaks from 2.84 to $2.85 \mathrm{MHz}$. The broad peaks were not seen in the persistent plasma line of 3 February. Figure 4 shows temporal variations in foF 2 measured with the ionosonde and height-averaged SNR of the diagnostic-radar backscatter power for the 4 February 2005 case. Enhancements of the plasma line did not persist after 0336 UT as shown in Figure 4. The operational mode of the diagnostic radar was switched from the upshifted plasma line measurement to the downshifted one at 0340 UT. Persistent plasma line enhancements were not clearly seen after the fortuitous measurement switch; but we think that the mode change is not the significant reason to stop the persistent enhancement. This is because the pulse beginning at 0337 UT did not show persistent enhancements, although the diagnostic radar was still operated in the mode of upshifted plasma line measurement. The principal reason we consider is the background ionospheric change as shown in Figure 4.

[16] The upper panel of Figure 4 shows that values of foF 2 from 0300 to 0330 UT remained almost constant around $3.2 \mathrm{MHz}$, then decreased to about $2.9 \mathrm{MHz}$ from 0330 to 0350 UT. After 0350 UT, values of $f o F 2$ were lower 


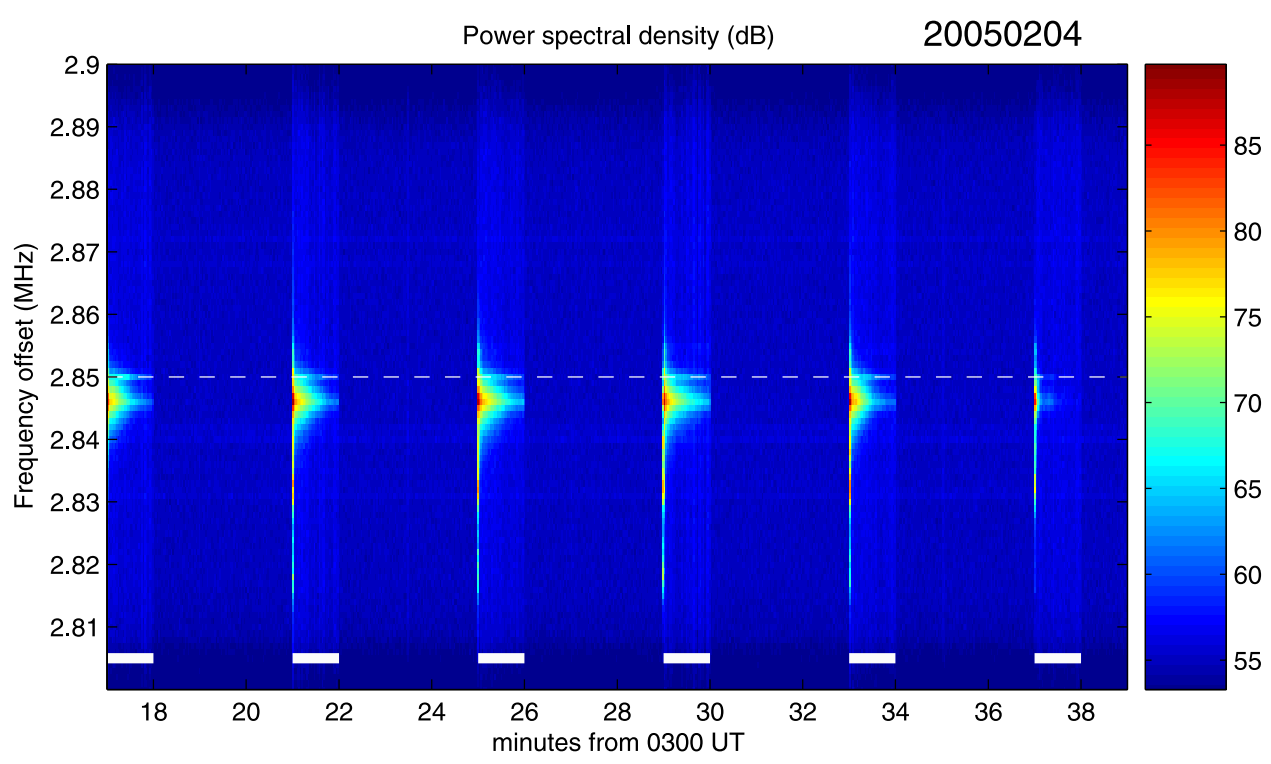

Figure 3. Color-coded time-frequency profile of power spectral density of the upshifted plasma line measured with the UHF diagnostic radar from 0317 to 0339 UT on 4 February 2005. White thick line shows time intervals for O-mode HF on. The format of figure is the same as Figure 1.

than the HF pump frequency of $2.85 \mathrm{MHz}$ for almost all the time. The HF pump frequency that was used when persistent plasma line enhancements were observed was slightly lower than $f_{o} F 2$. This is the identical relationship that is found for the 3 February case.

\subsection{Case Study on 5 February 2005}

[17] Figure 5 shows color-coded time-frequency profile of PSD of the downshifted plasma line from 0134 to 0138 UT on 5 February 2005. The figure is plotted using
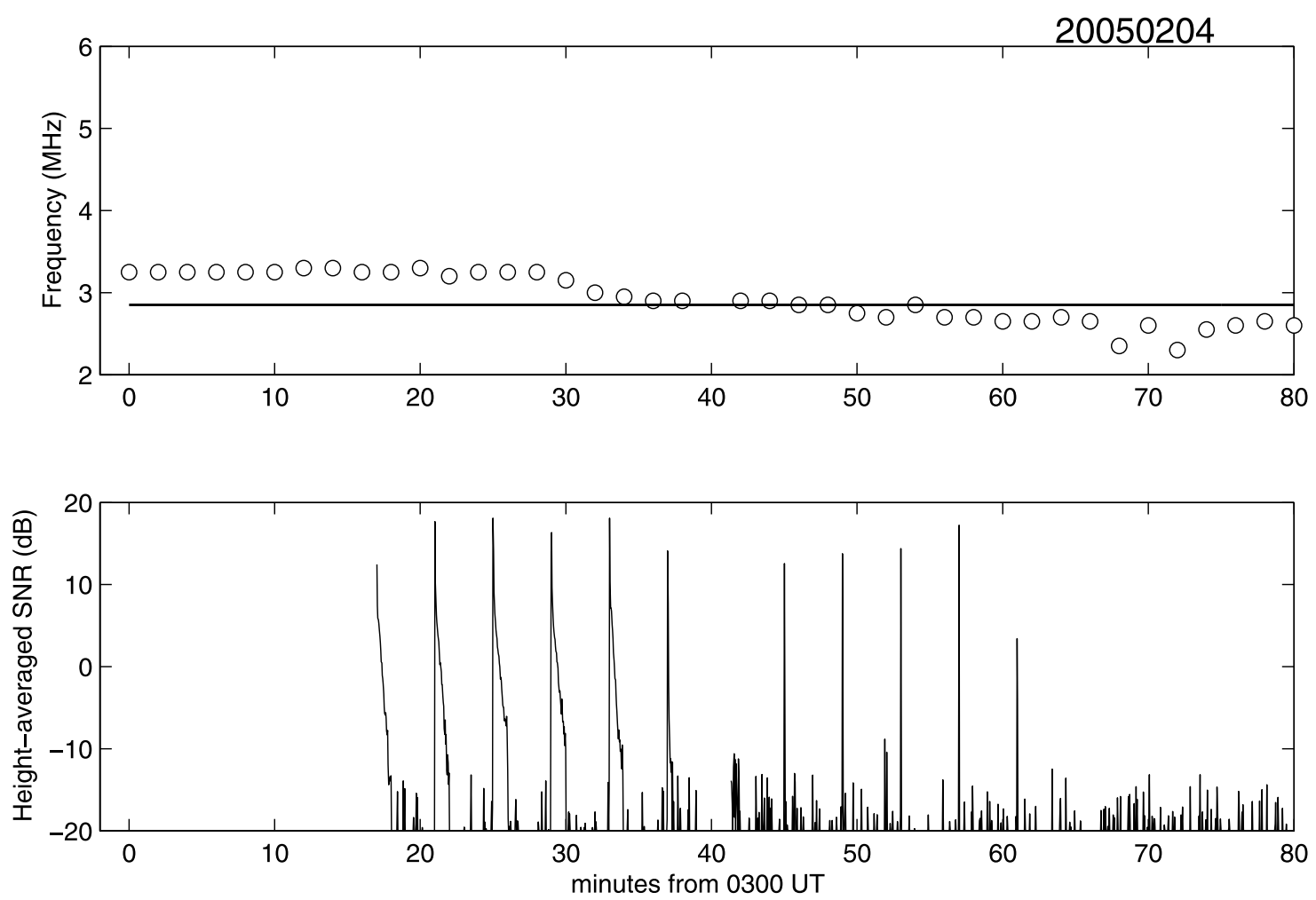

Figure 4. Temporal variations in $f o F 2$ measured with the HAARP ionosonde and the HF pump frequency of $2.85 \mathrm{MHz}$ from 0300 to 0420 UT on 4 February 2005 (upper panel). The lower panel shows temporal variations in the height-averaged SNR measured with the UHF diagnostic radar. The operational mode of the diagnostic radar was switched from the upshifted plasma line measurement to the downshifted one at $0340 \mathrm{UT}$. 


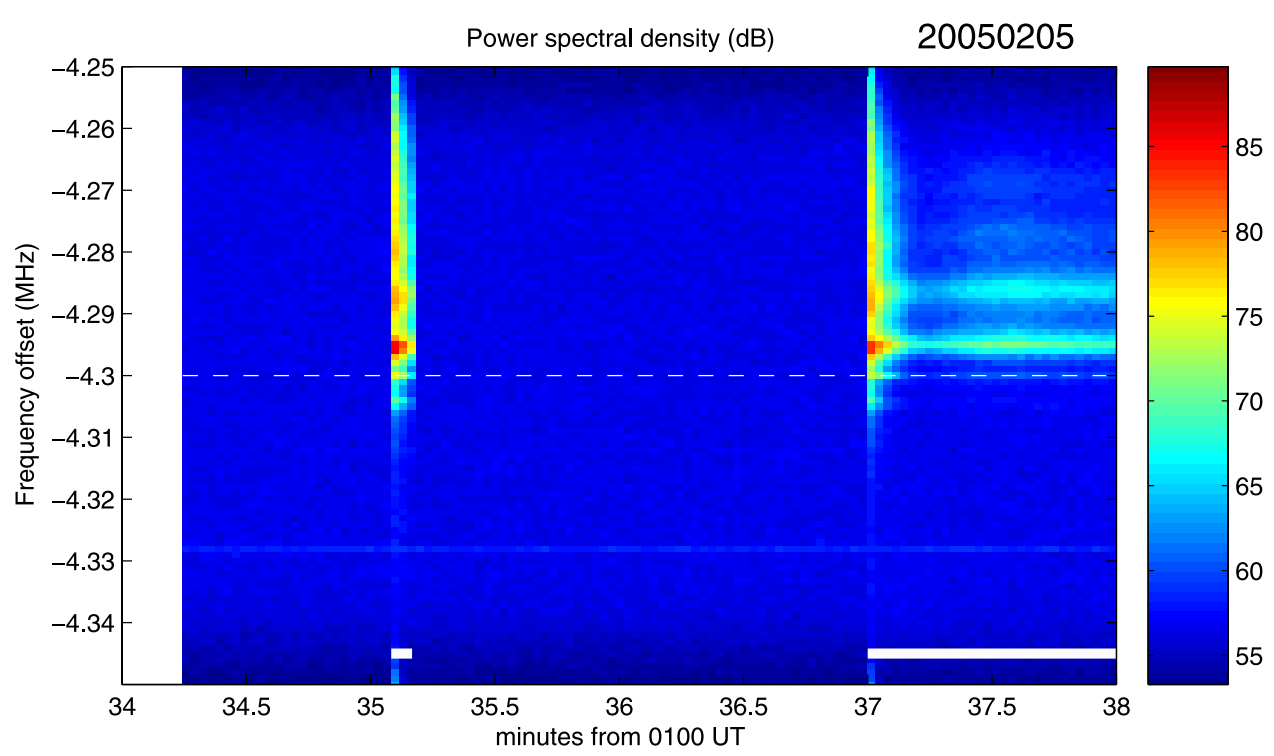

Figure 5. Color-coded time-frequency profile of power spectral density of the downshifted plasma line measured with the UHF diagnostic radar from 0134 to 0138 UT on 5 February 2005. The format of figure is the same as Figure 1.

data integrated for $2 \mathrm{~s}$. The purely growing mode can be clearly seen at $4.3 \mathrm{MHz}$, and the decay lines and the first and second cascade lines are also identified. A peak appeared at frequency displaced larger frequency than $f_{\mathrm{HF}}$ may be the image decay line. Persistent enhancements appeared during both HF on periods, although persistent enhancement beginning at 0135 UT was induced for relatively short on-period of $5 \mathrm{~s}$. PSD for the second period had a minimum value at 0137:15 UT then remained at a certain saturation level during HF on. The decay line and one cascade line appeared soon after HF turn-on and persisted throughout the HF on period. The purely growing mode,
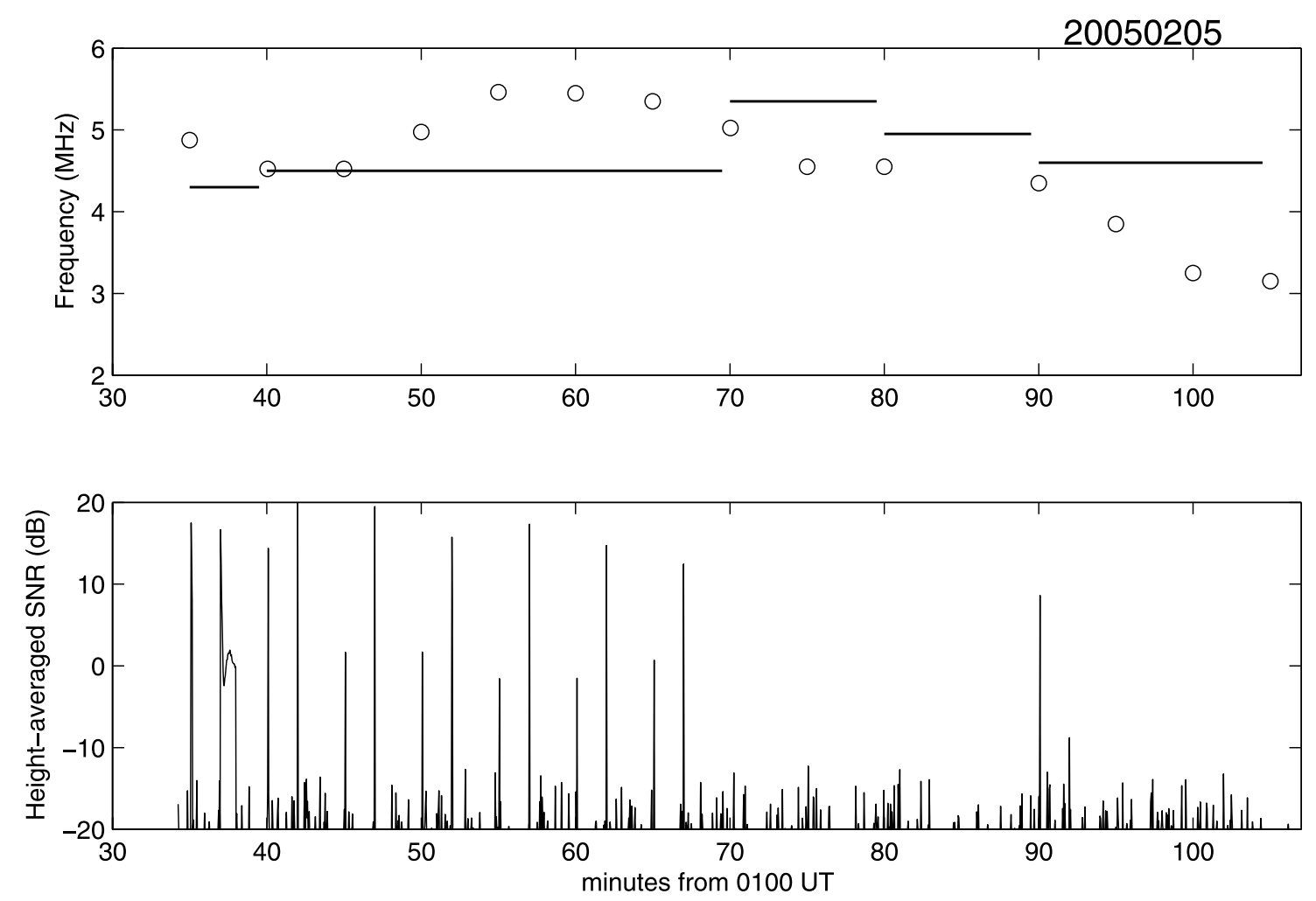

Figure 6. Temporal variations in $f o F 2$ measured with the HAARP ionosonde and the HF pump frequencies from 0134 to 0244 UT on 5 February 2005 (upper panel). The lower panel shows temporal variations in the height-averaged SNR measured with the UHF diagnostic radar. 
which appeared at $f_{\text {radar }}-f_{\mathrm{HF}}$, was seen for this case, although other two cases on 3 and 4 February did not show it clearly.

[18] Figure 6 shows temporal variations in $f_{O F}$ and the HF pump frequency and height-averaged SNR of the diagnostic-radar backscatter power. While persistent plasma line enhancements were seen from 0135 to 0138 UT when the HF pump frequency was slightly lower than foF 2 by a few hundred $\mathrm{kHz}$, persistent enhancements were not seen for other time periods. This result also suggests the identical characteristic about the relationship between $f_{o} F 2$ and the HF pump frequency with two other cases mentioned in the previous subsections.

[19] While the HF pump frequency of $4.5 \mathrm{MHz}$ was lower than foF 2 from 0150 to $0210 \mathrm{UT}$, there was no persistent plasma line enhancement. Frequency differences during this time period were in excess of $500 \mathrm{kHz}$, which is larger than those for other events associated with persistent plasma line enhancements (see Figures 2 and 4). This result suggests that there may be a maximum value of the frequency difference to generate persistent plasma line enhancements.

\section{Discussion}

[20] The three examples in this paper suggest that persistent enhancements of the UHF diagnostic-radar backscatter are induced when the HF pump frequency is slightly lower than foF 2 by a few hundred $\mathrm{kHz}$. The persistent enhancement is not generated when the HF pump frequency is equal to $f_{o F}$, that is, when the height gradient of the electron density is zero at the reflection height. The decay line and the cascade line are generated at the so-called matching height [DuBois et al., 1993a], which can be expressed as following [Stubbe et al., 1992]:

$$
z_{a}=z_{0}-12 \frac{V_{e}^{2}}{c^{2}} \frac{f_{\text {radar }}^{2}}{f_{H F}^{2}} H
$$

where $z_{0}$ is the reflection height, $V_{e}$, which is equal to

$$
\sqrt{k_{B} T_{e} / m_{e}}
$$

is the thermal velocity of electrons, $c$ is the speed of light, and $H$ is the plasma scale height, $k_{B}$ is the Boltzmann constant, $T_{e}$ is the electron temperature, and $m_{e}$ is the electron mass. While the matching height for the experiments cannot be determined precisely because the electron temperature is not available, the matching height may be located below the reflection height by $1.1-2.4 \mathrm{~km}$ for $f_{\mathrm{HF}}$ of $4.1-5.35 \mathrm{MHz}$ and by $3.7-5.0 \mathrm{~km}$ for $f_{\mathrm{HF}}$ of $2.85 \mathrm{MHz}$ if $H$ is $50 \mathrm{~km}$ and the electron temperature is in the 1500-2000 $\mathrm{K}$ level. However, if the reflection height is close to the $F_{2}$ peak height, where $H$ is significantly larger than the typical value (e.g., $50 \mathrm{~km}$ ), the matching height may be too far from the reflection height, and the ion-acoustic wave excited by PDI essentially damps before reaching the matching height. If this is the case, persistent enhancements of the plasma line may not be measured. These experimental results suggest that the persistent backscatter enhancement needs optimum height gradients in the ionospheric density or the plasma scale height around the matching height.
[21] Striations artificially induced by electromagnetic waves are local stationary depletions of the plasma density with scale of the order of a few meters across and several kilometers along the geomagnetic field line in the upper hybrid resonance region where a few kilometer below the HF pump wave reflection altitude. Field-aligned striations (FAS) of sufficient amplitudes can modify the refractive index of an O-mode wave in the vicinity of the upper-hybrid resonance [Robinson, 2002]. The scattering of electromagnetic waves into electrostatic waves at the upper-hybrid resonance altitude causes anomalous absorption, which can be suppressed when the HF pump frequency is close to (or at) electron gyroharmonics equal to or larger than 3 [Stocker et al., 1993; Stubbe et al., 1994; Honary et al., 1995, 1999; Robinson et al., 1996; Kosch et al., 2002]. In this case, during the entire duration of the HF transmitted pulse, these HF pump waves reach the matching height, where coupling to Langmuir and ion-acoustic waves takes place. These previous studies suggest that electron gyroharmonics are important to understand causality between the persistent plasma line enhancement and the modified ionospheric condition. In practice, persistent enhancements of the ion and plasma lines have been measured with the IS radar [Isham et al., 1987; Isham and Hagfors, 1993; Djuth et al., 1994; Honary et al., 1999; Dhillon and Robinson, 2005]. It is, however, noted that some papers suggest high absorption for the second gyroharmonic [Djuth et al., 2005; Kosch et al., 2005]. In this case anomalous absorption at the upper hybrid resonance greatly increases, and Bernstein modes become trapped in field-aligned irregularities then the shortscale irregularities are strongly excited [e.g., Fialer, 1974]. While the HF pump-induced plasma line should be much smaller, this scenario was in sharp contrast to results on 4 February. Next section addresses the electron gyroharmonics when the persistent plasma line enhancements were observed.

\subsection{Effects of the Electron Gyroharmonics}

[22] The electron gyrofrequency is a function of magnitude of the geomagnetic field as the equation is given by

$$
f_{\text {gyro }}=\frac{B e}{2 \pi m_{e}}
$$

where $B$ is the geomagnetic field magnitude, and $e$ is the charge of an electron. To estimate $B$, model results from the IGRF (International Geomagnetic Reference Field) are used in this paper thus $f_{\text {gyro }}$ is strongly dependent on the model results, although the geomagnetic field can fluctuate in association with geomagnetic activity by order of $100 \mathrm{nT}$. Uncertainty of the local plasma frequency and the electron gyrofrequency is the important issue when investigating the electron gyroharmonics at the reflection height. Electrongyrofrequency uncertainty due to geomagnetic-field fluctuations caused by ionospheric currents is addressed in this section. Uncertainty of the local plasma frequency from the ionosonde due to horizontal ionospheric inhomogeneity in the vicinity of the solar terminator is addressed in the next section.

[23] Geomagnetic field variations that cause electron gyrofrequency uncertainties of 50 and $10 \mathrm{kHz}$ are 1786 and $357 \mathrm{nT}$, respectively, from equation (2) assuming that 

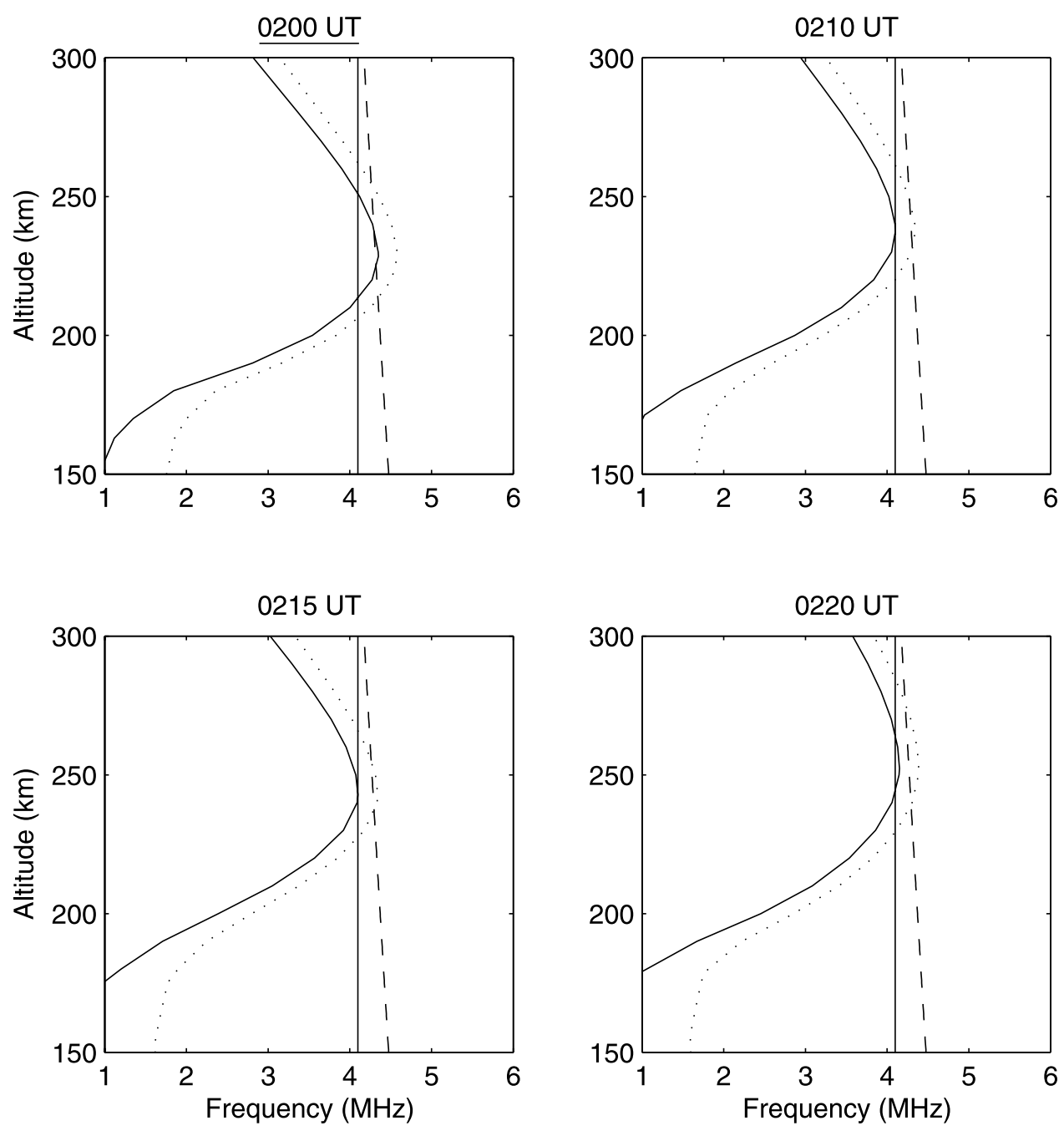

Figure 7. Height profile of the local plasma frequency estimated with the HAARP ionosonde (solid curve), the upper hybrid frequency (dotted curve), and the third harmonic electron gyrofrequency (dashed line) from 0200 to 0220 UT on 3 February 2005. The vertical solid line shows the HF pump frequency of 4.1 MHz. Persistent enhancements of the radar backscatter power were measured at time with underline.

horizontal ionospheric currents are distributed at $100 \mathrm{~km}$ height and the reflection height is $200 \mathrm{~km}$. This calculation suggests that the uncertainty is less than $10 \mathrm{kHz}$ according to magnetometer data during the experiments (not shown here). Uncertainty of the ionosonde data may be $\pm 2 \mathrm{~km}$ in height corresponding to about $3 \mathrm{kHz}$. These values should be remembered when discussing the gyroharmonics below.

[24] Figures 7, 8, and 9 show height profiles of the local plasma (solid curve) and the upper-hybrid (dotted curve) frequencies calculated using data from the ionosonde around time periods when persistent enhancements of the backscatter were observed. The HF pump frequency and the electron gyroharmonic frequency (dashed line) are also illustrated.

[25] Electron gyroharmonics for the case of 3 February in Figure 7 are different from those for the other two cases. For the case of 3 February, when persistent enhancements of the backscatter were measured, the local plasma frequency at the reflection height deviates clearly from the third electron gyroharmonic frequency comparing with the uncertainty estimated above; by contrast for the other two cases, the local plasma frequency at the reflection height is close to the second or third electron gyroharmonic frequencies. The latter two cases can be explained with the physical process of the previous studies as mentioned in the second paragraph of section 4, but the process is not appropriate for the case of 3 February. Since the pump frequency is $500 \mathrm{kHz}$ or more below $f_{o} F 2$ and is not equal to $f_{\text {gyro }}$ in the case of Figure 9 at 0150 UT, either argument could be the reason for the lack of persistent enhancement. The results suggest that the physical process is not perfect yet to explain the persistent backscatter enhancement, at least for results in the present paper.

\subsection{Ionospheric Inhomogeneity During the Experiments}

[26] While plasma lines are analyzed using data from geomagnetic field-aligned measurements of the UHF diagnostic radar, the ionosonde obtains most of its data from a 

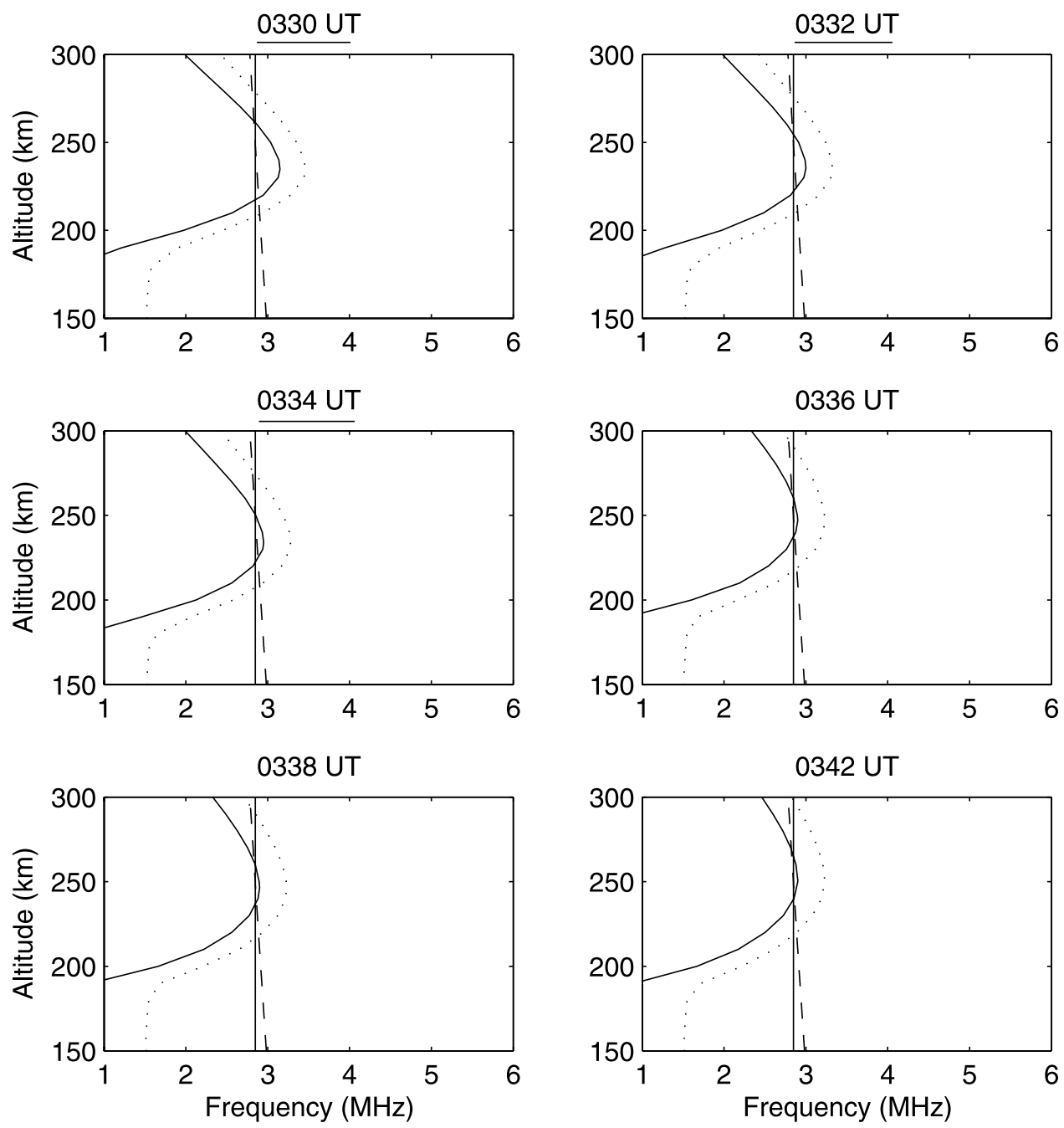

Figure 8. The format is the same as Figure 7 but for height profiles from 0330 to 0342 UT on 4 February 2005. The vertical solid and the dashed lines show the HF pump frequency of $2.85 \mathrm{MHz}$ and the second harmonic electron gyrofrequency, respectively.

wide beam directed vertically. Since the experiments were conducted at dusk, the ionospheric density might have horizontal gradients, and therefore the ionospheric density along the geomagnetic field line might be different from that at the zenith. In this section effects of the horizontal ionospheric inhomogeneity in the vicinity of the solar terminator on the ionospheric density are addressed.

[27] The horizontal distance between the zenith and the geomagnetic field line is about $60 \mathrm{~km}$ at $220 \mathrm{~km}$ height. Difference in the solar zenith angle $\chi$ due to the $60-\mathrm{km}$ distance is about $0.57^{\circ}$. The ionization rate is proportional to $\exp (-1 / \cos \chi)$, and differences in the ionization rate due to angle of $0.57^{\circ}$ are negligibly small except when the solar zenith angle is $89.43^{\circ}\left(=90^{\circ}-0.57^{\circ}\right)$, that is, just before the sunset. Since electron density variations in the $F$ region due to ionization and recombination while the solar terminator passes between two positions in the $F$ region are significantly smaller than background electron density, ionospheric inhomogeneity caused by the tilted solar radiation in the vicinity of the solar terminator is not important. Therefore the assumption of ionospheric homogeneity be- tween the zenith and the geomagnetic field line from HAARP is considered to be acceptable for the phenomena featured in this paper.

\section{Summary and Conclusions}

[28] This paper presents data from the first experimental campaign with the UHF diagnostic radar at HAARP. HF pump-induced plasma lines were observed with the UHF diagnostic radar. This paper focuses on persistent enhancements of the radar backscatter power during HF on, and presents three cases obtained on 3, 4, and 5 February 2005. All case studies show that persistent enhancements of the radar backscatter power are induced when the HF pump frequency is slightly lower than $f_{0} F 2$ by a few hundred $\mathrm{kHz}$ at the reflection height. The comparison studies suggest that the persistent enhancement may be related to the electrondensity height-gradient at the O-mode reflection height. On the other hand, the persistent enhancement does not appear when the HF pump frequency is equal to and higher than 

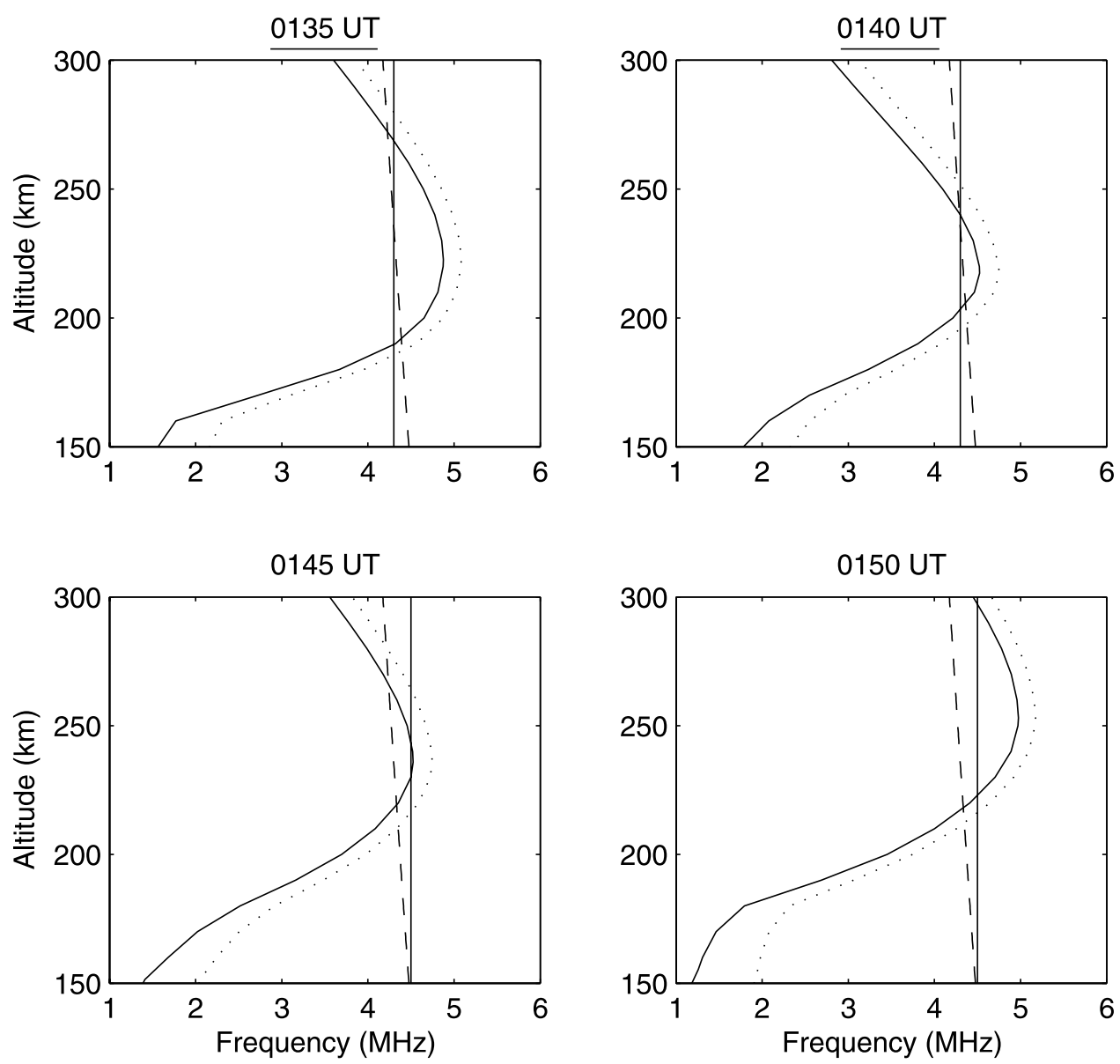

Figure 9. The format is the same as Figure 7 but for height profiles from 0135 to 0150 UT on 4 February 2005. The vertical solid line shows the HF pump frequency of 4.3 or $4.5 \mathrm{MHz}$.

$f_{0 F} 2$ at the reflection height or lower than $f_{0 F}$ by more than $500 \mathrm{kHz}$.

[29] Persistent enhancements measured on 4 and 5 February 2005 appeared when the HF pump frequency was close to the second or third electron gyroharmonic frequencies at the reflection height. This result is consistent with previous studies on coupling to Langmuir and ion-acoustic waves in the vicinity of the reflection height, and suggests that electron gyroharmonics play an important role in generating the persistent radar backscatter power [Stocker et al., 1993; Stubbe et al., 1994; Honary et al., 1995, 1999; Robinson et al., 1996; Kosch et al., 2002]. Persistent enhancements measured on 3 February 2005, however, show that the local plasma frequency at the reflection height is significantly different from the third electron gyroharmonic frequency, and this result is inconsistent with the theoretical prediction.

[30] Acknowledgments. The HAARP program is a Department of Defense project managed jointly by the U.S. Air Force and the U.S. Navy. This research was supported by grant N00014-03-1-0165 and other grants from the Office of Naval Research (ONR). The authors wish to thank HAARP personnel for their assistance in operating the experiments. The support of Lewis Duncan and William Gordon for assistance in initiating this research is greatly appreciated. The UHF diagnostic radar is a cooperative effort with the National Science Foundation and the HAARP program. The assistance of SRII personnel with the development of the radar under difficult environmental conditions has been most helpful. We also appreciate the extensive effort and helpful suggestions made by both reviewers in evaluating this paper.

[31] Arthur Richmond thanks James Sheerin and Brett Isham for their assistance in evaluating this paper.

\section{References}

Birkmayer, W., T. Hagfors, and W. Kofman (1986), Small-scale plasmadensity depletions in Arecibo high-frequency modification experiments, Phys. Rev. Lett., 57, 1008-1011.

Carlson, H. C., and L. M. Duncan (1977), HF excited instabilities in space plasmas, Radio Sci., 12, 1001-1013.

Cheung, P. Y., A. Y. Wong, T. Tanikawa, J. Santoru, D. F. DuBois, H. A. Rose, and D. Russell (1989), Short-time-scale evidence for strong Langmuir turbulence during HF heating of the ionosphere, Phys. Rev. Lett., 62, $2676-2679$.

Cheung, P. Y., D. F. DuBois, T. Fukuchi, K. Kawan, H. A. Rose, D. Russel, T. Tanikawa, and A. Y. Wong (1992), Investigation of strong Langmuir turbulence in ionospheric modification, J. Geophys. Res., 97(A7), $10,575-10,600$

Cheung, P. Y., M. P. Sulzer, D. F. DuBois, and D. A. Russell (2001), Highpower high-frequency-induced Langmuir turbulence in the smooth ionosphere at Arecibo. II. Low duty cycle, altitude-resolved, observations, Phys. Plasmas, 8(3), 802-812.

Dhillon, R. S., and T. R. Robinson (2005), Observations of time dependence and aspect sensitivity of regions of enhanced UHF backscatter associated with RF heating, Ann. Geophys., 23, 75-85.

Djuth, F. T. (1984), HF-enhanced plasma lines in the lower ionosphere, Radio Sci., 19(1), 383-394.

Djuth, F. T., C. A. Gonzales, and H. M. Ierkic (1986), Temporal evolution of the HF-enhanced plasma line in the Arecibo F region, J. Geophys. Res., 91(A11), 12,089-12,107.

Djuth, F. T., M. P. Sulzer, and J. H. Elder (1990), High resolution observations of HF-induced plasma waves in the ionosphere, Geophy. Res. Lett. 17(11), 1893-1896. 
Djuth, F. T., P. Stubbe, M. P. Sulzer, H. Kohl, M. T. Rietveld, and J. H. Elder (1994), Altitude characteristics of plasma turbulence excited with the Tromsø superheater, J. Geophys. Res., 99(A1), 333-339.

Djuth, F. T., B. Isham, M. T. Rietveld, T. Hagfors, and C. La Hoz (2004), First $100 \mathrm{~ms}$ of HF modification at Tromsø, Norway, J. Geophys. Res., 109, A11307, doi:10.1029/2003JA010236.

Djuth, F. T., T. R. Pedersen, E. A. Gerken, P. A. Bernhardt, C. A. Selcher, W. A. Bristow, and M. J. Kosch (2005), Ionospheric modification at twice the electron cyclotron frequency, Phys. Rev. Lett., 94, doi:10.1103/PhysRevLett.94.125001.

DuBois, D. F., A. R. Harvey, and D. Russell (1988), Power spectra of fluctuations in strong Langmuir turbulence, Phys. Rev. Lett., 61, 22092212.

DuBois, D. F., H. A. Rose, and D. Russell (1990), Excitation of strong Langmuir turbulence in plasmas near critical density: Application of HF heating of the ionosphere, J. Geophys. Res., 95(A12), 21,221-21,272.

DuBois, D. F., A. Hanssen, A. R. Harvey, and D. Russell (1993a), Space and time distribution of HF excited Langmuir turbulence in the ionosphere: Comparison of theory and experiment, J. Geophys. Res., 98(A10), 17,543-17,567.

DuBois, D. F., A. Hansen, H. A. Rose, and D. Russell (1993b), Excitation of strong Langmuir turbulence in the ionosphere: Comparison of theory and observations, Phys. Fluids B, 5(7), 2616-2622.

DuBois, D. F., D. Russell, and H. A. Rose (1995a), Reduced description of strong Langmuir turbulence from kinetic theory, Phys. Plasmas, 2(1), $76-96$.

DuBois, D. F., D. A. Russell, and H. A. Rose (1995b), Saturation spectra of the two-plasmon decay instability, Phys. Rev. Lett., 74(20), 3983-3986.

DuBois, D. F., D. A. Russell, P. Y. Cheung, and M. P. Sulzer (2001), Highpower high-frequency-induced Langmuir turbulence in the smooth ionosphere at Arecibo. I. Theoretical predictions for altitude-resolved plasma line radar spectra, Phys. Plasmas, 8(3), 791-801.

Duncan, L. M., and J. P. Sheerin (1985), High-resolution studies of the HF ionospheric modification interaction region, J. Geophys. Res., 90(A9), $8371-8376$

Fejer, J. A., and Y. Y. Kuo (1973), Structure in the nonlinear saturation spectrum of parametric instabilities, Phys. Fluids, 16(9), 1490-1496.

Fejer, J. A., M. P. Sulzer, and F. T. Djuth (1991), Height dependence of the observed spectrum of radar backscatter from HF-induced ionospheric Langmuir turbulence, J. Geophys. Res., 96(A9), 15,985-16,008.

Fialer, P. A. (1974), Field-aligned scattering from a heated region of the ionosphere: Observations at HF and VHF, Radio Sci., 9, 923-940.

Hagfors, T., W. Kofman, H. Kopka, P. Stubbe, and T. Äijanen (1983), Observations of enhanced plasma lines by EISCAT during heating experiments, Radio Sci., 18(6), 861-866.

Hanssen, A., E. Mjølhus, D. F. DuBois, and H. A. Rose (1992), Numerical test of the weak turbulence approximation to ionospheric Langmuir turbulence, J. Geophys. Res., 97(A8), 12,073-12,091.

Honary, F., A. J. Stocker, T. R. Robinson, T. B. Jones, and P. Stubbe (1995), Ionospheric plasma response to $\mathrm{HF}$ radio waves operating at frequencies close to the third harmonic of the electron gyrofrequency, J. Geophys. Res., 100(A11), 21,489-21,501.

Honary, F., T. R. Robinson, D. M. Wright, A. J. Stocker, M. T. Rietveld, and I. McCrea (1999), First direct observations of the reduced striations at pump frequencies close to the electron gyroharmonics, Ann. Geophys., 17, $1235-1238$

Isham, B., and T. Hagfors (1993), Observations of the temporal and spatial development of induced and natural plasma lines during HF modification experiments at Arecibo using chirped incoherent scatter radar, J. Geophys. Res., 98(A8), 13,605-13,625.

Isham, B., W. Birkmayer, T. Hagfors, and W. Kofman (1987), Observations of small-scale plasma density depletions in Arecibo HF heating experiments, J. Geophys. Res., 92(A5), 4629-4637.

Isham, B., C. La Hoz, M. T. Rietveld, T. Hagfors, and T. B. Leyser (1999), Cavitating Langmuir turbulence observed during high-latitude ionospheric wave interaction experiments, Phys. Rev. Lett., 83, 2576-2579.

Kantor, I. J. (1974), High frequency induced enhancements of the incoherent scatter spectrum at Arecibo, 2, J. Geophys. Res., 79(1), 199-208.

Kohl, H., and M. T. Rieveld (1996), Harmonics of the ion acoustic frequency in the heater induced ion spectrum, J. Geophys. Res., 101(A32), $5391-5395$

Kohl, H., H. Kopka, P. Stubbe, and M. T. Rietveld (1993), Introduction to ionospheric heating experiments at Tromsø - II. Scientific problems, J. Atmos. Terr. Phys., 55, 601-613.

Kosch, M. J., M. T. Rietveld, A. J. Kavanagh, C. Davis, T. K. Yeoman, F. Honary, and T. Hagfors (2002), High-latitude pump-induced optical emissions for frequencies close to the third electron gyro-harmonic, Geophys. Res. Lett., 29(23), 2112, doi:10.1029/2002GL015744.
Kosch, M. J., T. Pedersen, J. Hughes, R. Marshall, E. Gerken, A. Senior, D. Sentman, M. McCarrick, and F. T. Djuth (2005), Artificial optical emissions at HAARP for pump frequencies near the third and second electron gyro-harmonic, Ann. Geophys., 23(5), 1585-1592.

Muldrew, D. B., and R. L. Showen (1977), Height of the HF-enhanced plasma line at Arecibo, J. Geophys. Res., 82(29), 4793-4804.

Nicholson, D. R., G. L. Payne, R. M. Downie, and J. P. Sheerin (1984), Solitons versus parametric instabilities during ionospheric heating, Phys. Rev. Lett., 52, 2152-2155.

Payne, G. L., D. R. Nicholson, R. M. Downie, and J. P. Sheerin (1984), Modulational instability and soliton formation during ionospheric heating, J. Geophys. Res., 89(A12), 10,921-10,928.

Perkins, F. W., C. Oberman, and E. J. Valeo (1974), Parametric instabilities and ionospheric modification, J. Geophys. Res., 79(10), 1478-1496.

Petviashvilli, V. I. (1976), Formation of three-dimensional Langmuir solitons by an intense radio wave in the ionosphere (in Russian), Fiz. Plazmy, 2, 450. (Sov. J. Plasma Phys., Engl. Transl., 2, 247.)

Rietveld, M. T., B. Isham, H. Kohl, C. La Hoz, and T. Hagfors (2000), Measurements of HF-enhanced plasma and ion lines at EISCAT with high-altitude resolution, J. Geophys. Res., 105(A4), 7429-7439.

Robinson, T. R. (2002), Effects of multiple scatter on the propagation and absorption of electromagnetic waves in a field-aligned-striated cold magneto-plasma: Implications for ionospheric modification experiments, Ann. Geophys., 20, 41-55.

Robinson, T. R., F. Honary, A. J. Stocker, T. B. Jones, and P. Stubbe (1996), First EISCAT observations of the modification of F-region electron temperatures during RF heating at harmonics of the electron gyro frequency, J. Atmos. Terr. Phys., 58, 385-395.

Russell, D., D. F. DuBois, and A. R. Harvey (1988), Nucleation in twodimensional Langmuir turbulence, Phys. Rev. Lett., 60, 581-584.

Sheerin, J. P., D. R. Nicholson, G. L. Payne, P. J. Hansen, J. C. Weatherall, and M. V. Goldman (1982), Solitons and ionospheric modification, J. Atmos. Terr. Phys., 44, 1043-1048.

Showen, R. L., and D. M. Kim (1978), Time variations of HF-induced plasma waves, J. Geophys. Res., 83(A2), 623-628.

Sprague, R. A., and J. A. Fejer (1995), Simultaneous excitation of parametric decay cascades and of the oscillating two-stream instability in one-dimensional numerical simulations based on Zakharov's equations, J. Geophys. Res., 100(A12), 23,959-23,972.

Stocker, A., J. F. Honary, T. R. Robinson, and T. B. Jones (1993), Anomalous absorption during artificial modification at harmonics of the electron gyrofrequency, J. Geophys. Res., 98, 13,627-13,634.

Stubbe, P. (1996a), The ionosphere as a plasma laboratory, in Modern Ionospheric Science, edited by H. Kohl, R. Rüster, and K. Schlegel, pp. 274-321, Eur. Geophys. Soc., Katlenburg-Lindau, Germany.

Stubbe, P. (1996b), Review of ionospheric modification experiments at Tromsø, J. Atoms. Terr. Phys., 58, 349-368.

Stubbe, P., H. Kopka, M. T. Rietveld, A. Frey, and P. Hoeg (1985), Ionospheric modification experiments with the Tromsø heating facility, J. Atmos. Terr. Phys., 47, 1151-1163.

Stubbe, P., H. Kohl, and M. T. Rietveld (1992), Langmuir turbulence and ionospheric modification, J. Geophys. Res., 97(A5), 6285-6297.

Stubbe, P., A. J. Stocker, F. Honary, T. R. Robinson, and T. B. Jones (1994), Stimulated electromagnetic emissions and anomalous HF wave absorption near electron gyroharmonics, J. Geophys. Res., 99(A4), 6233-6246.

Sulzer, M. P., and J. A. Fejer (1994), Radar spectral observations of HFinduced ionospheric Langmuir turbulence with improved range and time resolution, J. Geophys. Res., 99(A8), 15,035-15,050.

Walker, J. C. G. (1979), Active experimentation with the ionospheric plasma, Rev. Geophys., 17, 534-544.

Weatherall, J. C., J. P. Sheerin, D. R. Nicholson, G. L. Payne, M. V. Goldman, and P. J. Hansen (1982), Solitons and Ionospheric heating, J. Geophys. Res., 87(A2), 823-832.

Zakharov, V. E. (1972), Collapse of Langmuir waves, Sov. Phys. JETP, 35, $908-914$.

P. A. Bernhardt, Plasma Physics Division, Naval Research Laboratory, 4555 Overlook Avenue SW, Washington, DC 20375, USA.

F. T. Djuth, Geospace Research, Inc., 550 N. Continental Boulevard, Suite 110, El Segundo, CA 90245, USA.

C. J. Heinselman, SRI International, 333 Ravenswood Avenue, Menlo Park, CA 94025-3493, USA.

M. J. Kosch, Communication Systems, Lancaster University, Lancaster LA1 4YR, UK.

S. Oyama and B. J. Watkins, Geophysical Institute, University of Alaska Fairbanks, 903 Koyukuk Drive, P. O. Box 757320, Fairbanks, AK 99775 7320, USA. (soyama@gi.alaska.edu) 